\title{
El real-imaginario de Marilia Samper
}

\author{
Eduardo Chivite Tortosa
}

\section{(2) OpenEdition}

\section{Journals}

Edición electrónica

URL: https://journals.openedition.org/cher/1064

DOI: $10.4000 /$ cher.1064

ISSN: 2803-5992

\section{Editor}

Presses universitaires de Strasbourg

\section{Edición impresa}

Fecha de publicación: 11 julio 2019

Paginación: 39-52

ISBN: 979-10-344-0046-1

ISSN: 1968-035X

\section{Referencia electrónica}

Eduardo Chivite Tortosa, «El real-imaginario de Marilia Samper», reCHERches [En línea], 22 | 2019, Publicado el 07 octubre 2021, consultado el 17 noviembre 2021. URL: http://journals.openedition.org/ cher/1064 ; DOI: https://doi.org/10.4000/cher.1064 


\title{
El real-imaginario de Marilia Samper
}

\author{
Eduardo Chivite Tortosa ${ }^{1}$
}

$\mathrm{M}$ arilia Samper nació en São Paulo, Brasil, en 1974. Vivió una infancia nómada, como ella misma cuenta: "Cumplí los tres años en Salvador de Bahía, los cuatro en Bagdad, [...] los catorce en Sevilla” (Samper 2018). Allí se quedará hasta que se marche a estudiar Dirección Escénica y Dramaturgia al Institut del Teatre de Barcelona, donde actualmente reside. Estudió interpretación en el Instituto del Teatro de Sevilla, entrando en contacto con diferentes compañías independientes: Viento Sur, Teatro Sintético o La Matrona, y también con la compañía del Centro Andaluz de Teatro (Anónimo 2011a).

El Instituto del Teatro de Sevilla fue un proyecto inaugurado en 1981, donde se facilitó una enseñanza multidisciplinar que atrajo a los mejores directores y actores del momento (Lapeña 1996). En 1988, año en que se funda el Centro Andaluz de Teatro (CAT), el Instituto de Teatro se integró con este, pasando a ser el departamento de formación actoral del CAT, en el cual también había un departamento de producción teatral y de documentación. En este contexto, en el año 1997, se convocó el primer certamen del Premio Miguel Romero Esteo, siendo responsable de su organización el propio Centro Andaluz de Teatro. Este premio tomó como modelo a seguir el Premio Nacional de jóvenes dramaturgos Marqués de Bradomín, que ya entonces dio nombre a la anterior generación: los bradomines. Hoy, siguiendo esa estela, podemos hablar de la última generación de autores "andaluces", aunque, en realidad, no cabe reducirla a una mera cuestión geográfica.

Es en este momento en el que la dramaturga Marilia Samper hace su aparición con los títulos 405 y Menú del día, su primera y segunda obra escritas hasta la fecha, por las que es merecedora del primer accésit del Premio Miguel Romero Esteo y, a su vez, también, ambas obras, del primer accésit del Premio Marqués de Bradomín, en los años 2001 y 2002, respectivamente. A raíz de estos premios, las dos fueron estrenadas bajo dirección de Paco Montes, 405

1 Eduardo Chivite Tortosa, Departamento de Dirección y Ciencias del EspectáculoEscuela Superior de Arte Dramático de Sevilla. 
por el CAT en el Teatro Central de Sevilla (2002), y Menú del día en 2007 en el Teatro Sarobe (Urnieta). Las dos se publicaron por el Centro Andaluz de Teatro (Rubio, Samper \& Gutiérrez 2001; Salvatierra, Samper \& Montero 2002) y por la editorial Naque, al año siguiente de merecer el Bradomín (Campos, Samper \& Gomar 2001; Busto, Salvatierra \& Samper 2002). Según sus propias palabras: "en mis ratos libres, y casi por casualidad, empecé a escribir" (Samper 2018), y sí, efectivamente, "cuando iba de gira como actriz en un Otelo del Centro Andaluz de Teatro empezó a escribir para entretenerse" (Anónimo 2012a). El texto en cuestión era precisamente 405, su primera obra de teatro.

Es una obra inquietante en muchos aspectos: una pareja de desconocidos que se ven obligados a compartir la misma habitación por un error en recepción, una llamada que nunca suena, un acuerdo entre los dos para no saber nada el uno del otro. Pero el verdadero conflicto no nace de lo que sucede, sino del "imaginario":

MUJER. No pretendo romper nuestro acuerdo ni descubrir nada. Solo imagino. Es una forma de matar el tiempo. Si no voy a saber nada de usted tal vez pueda inventarlo, ¿no? Así como inventamos nuestros nombres (Rubio, Samper \& Gutiérrez 2001: 33).

Justo antes de que los personajes tengan su primer encuentro amoroso, ella le dice: "Por favor, Leo, démelo. Deme algo de cariño [...] Imagine que soy otra" (Ibídem: 37). Ana imagina que Leo ha matado al marido de su amante y que la llamada que espera es de ella. "No seas tonto. No llamará. Te utilizó para deshacerse de su marido" (Ibídem: 39). Cada deseo, en la poética de Marilia Samper, termina volviéndose real: "entre nosotros ya cuesta saber qué es real y qué es inventado" (Ibídem: 40). Pero ella termina rompiendo su pacto: ha huido de su marido, está esperando para ir a la estación, el amor de su vida la llevará a un lugar "donde tú no estarás..., donde tú no sabrás que existo" (Ibídem: 45). La llamada suena, Ana teme que sea la amante de Leo y, cuando él lo coge, arranca el cable. Él la rechaza definitivamente: "te quiero lejos" (Ibídem: 47). De nuevo el deseo...

Me gusta mucho escribir sobre el anhelo y la frustración. El deseo. Siempre vivimos con esta inquietud y este es el significado de estar vivos, el estar constantemente a la búsqueda de algo. [...] leyendo filósofos he visto la importancia de tener fe, en el sentido de proyectar en el futuro (Barderi 2015).

Mientras que él está en el baño, ella recoge sus cosas: "Mi desconocido sin nombre. Solo quería tenerte conmigo. Se nos da bien inventar. Podríamos inventar la vida que más nos guste para los dos" (Ibídem: 47). Cuando vuelve, Ana no está; en recepción niegan una y otra vez que se haya dado un error en la reserva de su habitación. "Hombre. Ella debía tomar un tren... [...] Recepcionista. Lo lamento, señor, pero en esta ciudad carecemos de estación de ferrocarriles" (Ibídem: 48). El último deseo de Leo se ha vuelto real.

En Menú del día hay un paratexto de una telenovela que las dos cocineras de la obra siguen apasionadamente y que mantiene un peculiar paralelismo con la acción de la obra. El primer elemento imaginario es el de ellas dos hablando de poner lentejas con cianuro y cagajón de vaca empanado (Salvatierra, Samper \& Montero 2002: 33). El conflicto toma carta de naturaleza en un concurso, 
quien lo gane podrá asistir al rodaje de La Impostora en California y cenar con los protagonistas de la serie. Una de ellas ha robado el teléfono del encargado. La ilusión por ganar se va convirtiendo en una obsesión alimentada por la vida real que les rodea: el marido de Pepa, un borracho por el que se desvive, $y$, en contraste, el imaginario que interfiere con la realidad: "una se pone a ver hombres en la tele como el Richard, que dice unas cosas tan bonitas [...] y te encuentras que el que tienes al lado te trata como un trasto" (Ibídem: 41). Cuando el encargado las descubre, lo golpean y lo meten en un saco de patatas. Ya no hay marcha atrás, la única posibilidad es ganar el premio y huir a California. Siguen preparando la comida para no levantar sospechas, medio borrachas, le rematan con el rodillo y empiezan a añadir a la comida amoníaco y otros productos de limpieza, como imaginaban al principio de la obra. Antes de marcharse, se sirven un recipiente para su cena y para la del marido. La obra termina con el paratexto de la telenovela: “-Vamos a hacer un viaje. —Adónde iremos? —Lejos. — ¿Muy lejos? -Mucho” (Ibídem: 56).

Quizá sea como afirma Terry Eagleton: “¿Cómo podemos saber lo que deseamos hasta que le damos expresión? [...] De acuerdo con Freud, en lo más profundo del deseo anida una deficiencia o fallo que desvía su objetivo y lo pervierte" (Eagleton 2017: 137-138). En el caso de Ana y Leo, de Pepa y Chelo, en parte es verdad, cuando el imaginario se vuelve real se pervierte, pero va más lejos, el imaginario se vuelve real desde el mismo momento en que se verbaliza: el real-imaginario. De hecho, al final, Pepa y Chelo consiguen su viaje lejos de esas vidas de las que deseaban escapar. ¿Ocurre algo parecido en todas las obras de Marilia Samper?

La autora confiesa que en el Instituto del Teatro de Sevilla descubrió su inclinación por la dirección y que fue eso, esencialmente, lo que en 2001 la animó a ir a Barcelona. De hecho, hasta 2009 no comienza a desarrollar su actividad como escritora, entendida desde entonces como un oficio, compaginado con su otra faceta como directora. Hasta 2006 no habrá un nuevo título, Un verdadero cowboy. Esta obra será distinguida con el segundo premio del VI Concurso Nacional de Dramaturgia Carlos Carvalho de Porto Alegre, Brasil, en 2006, editada por la Editorial da Cidade en 2008 y estrenada bajo dirección de Liane Venturella en agosto de 2011 en la sala La Photo (Porto Alegre). Pero también mereció el Premio Juan de Timoneda de teatro en castellano de la XXIV Edicios de Premis Literaris Ciutat de Valencia 2006².

Julio Conte, en el prólogo de la edición de Un verdadero cowboy, afirma que el anciano protagonista, que acaba de quedar viudo, maltratado por su hija, "evoca, en su imaginación, la figura de John Wayne [...] la fantasía como vía de escape [...] frente a la muerte inminente [...] [quien] lo encamina hacia el horizonte

2 Este año participa, junto a la mayor parte de la nómina del Romeo Esteo, en el proyecto que Alfonso Zurro organizó para el Día Mundial del Teatro, representado en la Escuela Superior de Arte Dramático de Sevilla, siendo el primer espectáculo de microteatro realizado en Andalucía. Su pieza se tituló Amor de madre (Zurro 2006). 
de lo desconocido" (Basbaum, Samper \& Lara Puiati 2008). El primer deseo de la hija se expresa con rotundidad: "Necesito estar en silencio. ¿Lo entiendes?". En la escena tercera llama la atención la primera manifestación de debilidad del anciano: "Me daba miedo el silencio". Después, otra vez el deseo, expresado en voz alta: "Papá. [...] Intenta echarte algún amigo". Y, de hecho, la frase siguiente: “John WAYNE. ¡Eh, amigo!”, que parece haber venido para infundirle los arrestos que su hija espera del maltrecho anciano. Cuando llega su final, la realidad y lo imaginario se confunden hasta que la fantasía, como metáfora de la muerte, se impone con la imagen del desierto y John Wayne grita: “¡Yiiiiijuuuuuuu!”. En una entrevista Marilia afirma: "soy destructiva por naturaleza. Sin miedo a tirar nada [...] ¿Reiteración? A la mierda. [...] Pulir, pulir, pulir. Lo que sí hago al corregir un texto es volver atrás en la lectura para encontrar conexiones" (Barderi 2015). "Necesito estar en silencio. ¿Lo entiendes?".

Como directora hay que destacar trabajos tempranos, como la dirección de Fosc en Teatre Estudi durante 2006, una dramaturgia no textual desarrollada por la misma Samper; en diciembre de 2007, la dirección de Nowhereville o La foscor al país dels cecs y, en junio de 2008, de Submergir-se en l'aigua, ambas de Helena Tornero, representadas, igualmente, en el Teatre Estudi ${ }^{3}$. También en $2008^{4}$ participará vía correo electrónico en un proyecto de escritura coral, constituido por seis autores (cuatro de los cuales forman parte de la nómina del Romeo Esteo) bajo la coordinación de José Sanchis Sinisterra, para el Teatro del común, titulado La orilla perra del mundo, que será publicado por Akal (Sanchis 2008).

[...] este proyecto se planteó desde sus inicios como un trabajo de escritura colectiva basado en la poética de la fragmentariedad, contando con un equipo formado por autores de la última generación. [...] a partir de un tema común -la situación actual de lo contemplado en la Declaración de Derechos Humanos (Sanchis, Vázquez \& Luque 2008: 7-8).

Hacia 2009, Anna Güell y Mercè Anglès, fundadoras de Q-Ars, contactan con Marilia para que desarrolle la parte textual de un proyecto centrado en la figura de Fedra. Querían trabajar desde la influencia del Hipólito de Eurípides, la Fedra de Racine y Phaedra's Love de Sarah Kane (Anónimo 2011b). El resultado fue una obra titulada F3dra. Pleasure and Pain, cuyo subtítulo es fruto de la canción homónima de Ben Harper. A pesar de empezar a escribirse en 2009 no se estrenaría hasta septiembre de 2011 en la Sala Beckett, bajo dirección de Pep Pla y producida y representada por la compañía Q-Ars Teatre.

La acción ocurre durante el mes de febrero de 1999. En un cuarto de la unidad de psiquiatría de un hospital de Londres, en un pub de un barrio

3 El Teatre Estudi es una pequeña sala experimental del Institut del Teatre con múltiples posibilidades de disposición y capacidad para 120 espectadores.

4 Este año se le encarga una adaptación dramática del Otelo de Shakespeare, que se titulará Otelo (Blowing in the wind), consistente en una versión para cinco actores y una canción de Bob Dylan que, desgraciadamente, no llegó a ser representada por falta de financiación. 
cualquiera [...] y en el camerino de un teatro de Broadway tres años antes. El personaje de Sarah es una ficción sobre la figura de la dramaturga británica Sarah Kane (Anónimo, 2012b) ${ }^{5}$.

"No quiero que te quedes sin pedir un deseo [...] Freddy. Tengo uno. Billy acerca la cerilla encendida a los labios de Freddy. Ella cierra los ojos y después sopla la llama". Con este comienzo el paralelismo entre Fedra e Hipólito y Freddy y Billy (su cuñado) está servido. Cuando Sarah en la unidad de psiquiatría le pregunta al enfermero si hay algo que desee tanto que de no obtenerlo solo le den ganas de morir, él le devuelve la pregunta; Sarah responde: "papel”. Tres años antes, conversando con su admirada-amada Vera, actriz de Broadway, hablando de escribir para ella su propia versión de Fedra, Vera le pregunta cómo imagina a Fedra y Sarah afirma: "Sería una mujer cualquiera, tal vez. Bajo la luz púrpura del pub, se nos aparece Freddy, la camarera”. A partir de aquí el imaginario y la realidad se entrecruzan: Sarah escribe en el sanatorio acerca de Freddy, incluso, sobre su propia piel, a quien conocerá en su bar años después del suicidio de Vera. La conversación de Vera y Sarah sobre la escritura de su Fedra y la vida de Freddy son la misma cosa, ocurre al mismo tiempo, se alternan. Pero cuando Sarah conoce a Freddy y le habla de Vera, la conversación de Vera y Sarah se vuelve un flashback que se representa en directo ante el espectador, donde Vera traiciona a Sarah con el joven actor, al que engatusa con versos de su actuación, interactuando así la "literatura" con la propia realidad. ¿Cabe mejor manifestación del real-imaginario? "Me ha encantado hablar contigo, Fedra. [...] Es Freddy...”.

Cuando Billy, en medio de un fraternal beso, movido por el deseo de proteger a Freddy de su hermano, que la maltrata, es correspondido apasionadamente, el arquetipo del casto Hipólito emerge y con él el de la desdeñada Fedra: "(Cruel). Ahora sé porque te hace esas cosas". Cuando el enfermero le cuenta el caso a Sarah, ella solo susurra: "Fedra... EnFERmero. Podrías probar a escribir sobre eso. SARAh. [...] Probablemente ya lo haya escrito". Sarah escupe las pastillas, seguidamente, lo espectral, lo alucinatorio, ocupa la escena, libre de los efectos de la medicación... Vera recita un fragmento del coro del Hipólito de Eurípides; las tres mujeres se van confundiendo en una, hablan en parejas, luego en conjunto: "Del techo de su casa va a colgar un lazo / y atarlo al cuello blanco", al tiempo Sarah va sacándose los cordones de sus botas [acotación de F3dra].

Aproximadamente, hacia finales de 2009, debió comenzar la coautoría de Dos punkis y un vespino, escrita junto a Llátzer García. Esta obra ganaría en 2010 el Premio de Escenificación del Institut del Teatre de Barcelona al mejor

5 Hay varias fuentes documentales que han requerido traducción bien del catalán, bien del rumano, por lo que todas las traducciones son libres y realizadas por el autor del artículo (mis disculpas). Las citas de las obras están tomadas de sus ediciones (cuando se indica número de página) o de los textos recogidos en la web oficial de Marilia Samper (en cuyo caso no se indica), aunque otros han tenido que ser facilitados en castellano por la autora. 
espectáculo de texto (Samper 2018)6, representándose en el teatro Gaudí del 10 de noviembre de 2011 al 15 de enero de 2012, bajo dirección de la propia Marilia Samper. De hecho, en una entrevista Marilia reconoce que del texto original al montaje ha habido bastantes modificaciones (Armengol s.f.). Es más, el montaje empieza por el final.

La noche de navidad, dos punkis, una chica vestida de gala y el dependiente de la gasolinera en la que están, bailan y beben pasándoselo bien; de golpe la chica marcha llorando y uno de los punkis la sigue. El dependiente absorto ante la situación pregunta: “¿Pero no lo estábamos pasando bien?, ¿qué ha pasado?”, a lo que el otro punki le responde: "Para entenderlo todo hay que saber el principio" (Bouma 2011).

Esta es la primera comedia de Samper y en ella el real-imaginario se vuelve, curiosamente, irónico, de ahí la gracia. Todo lo que se verbaliza termina siendo real, especialmente si lo dice el aterrado y políticamente correcto gasolinero, muy a su pesar: "Feliz Nochebuena", "Yo no quiero problemas aquí", "no me hagan daño", "me gustaría mucho poder alojarles aquí", "tiene usted también pensado quedarse aquí esta noche". Y Jota, uno de los punkis, es la voz de lo que paradójicamente solo es real en el imaginario colectivo: "Quién sabe si con tu ayuda no nos estarás salvando la vida, macho", "es así como se debe vivir y es así como se debe pensar".

Como directora, en 2011, vuelve a dirigir un texto de Helena Tornero, You're pretty and I'm drunk, estrenada en el prestigioso Teatre Lliure de Barcelona (Montjuïc), dentro del ciclo Ensayo Abierto, y un año más tarde, Suïcides, escrita por Llàtzer García y estrenada por la compañía Poca Cosa teatro en el Teatro Municipal de Bescanó el 11 de noviembre de 2012. Para el verano de ese mismo año, la notoria compañía Parking Shakespeare ${ }^{7}$ le solicita una versión y la dirección de la obra Trabajos de amor perdidos para su habitual espectáculo estival al aire libre.

En esta misma temporada, ahora como autora, hay que destacar L'ombra al meu costat, que se estrena del 3 al 27 de mayo de 2012, dentro del proyecto T6 ${ }^{8}$,

6 Al consultar la página web del Institut del Teatro aparece como "Millor projecte de teatre de text: Animal Migratoris de la Happy End Associació (2010)" (Anónimo s.f. a), se debe, según la propia Marilia, a que tuvieron que inscribir la obra con celeridad y que, más tarde, decidieron cambiar el nombre de la obra y de la compañía: La Brava, de la que es cofundadora.

7 "Parking Shakespeare es una compañía que cada verano ofrece un Shakespeare al aire libre y gratuito” (Anónimo s.f. b).

8 El Proyecto T6 es una iniciativa del Teatro Nacional de Cataluña, en que se encarga a seis autores una obra, "entre los grandes fenómenos comerciales y las propuestas más arriesgadas e independientes [para, así,] dar cabida a las obras de teatro de autores jóvenes (y no tanto) que buscan su sitio" (Barbany 2012). "El T6 nació con un objetivo múltiple: combatir el aislamiento del escritor mediante una serie de reuniones [...] [para] volver a involucrar al dramaturgo en el proceso de creación de un espectáculo, en el que participa desde las primeras lecturas" (Ginart 2005). 
en la Sala Tallers del Teatro Nacional de Cataluña. Esta obra será publicada por Arola Editors (Samper 2012) y, gracias al proyecto Fabulamundi. Playwriting Europe $^{9}$, será motivo de una lectura dramatizada el 25 de marzo de 2014 en la Sala Majestic del Teatro Odeon de Bucarest y de otras actividades en el Stückemarkt de Heidelberg (Anónimo 2017a), siendo traducida por Florin Galis e Iunia Mircescu. Versión al rumano que será dirigida en 2017 por Vlad Cristache "uno de los directores más aclamados de la generación más joven" (Anónimo 2017b) en la Sala Atelier Hall del Museo Nacional bajo producción del Teatro Nacional de Bucarest, "un lugar donde las experiencias de los actores y el aliento emocionado de los espectadores casi se tocan" (Ilis 2017), pasando a ser una de las piezas del repertorio teatral del TNB.

Se trata de tres historias aparentemente desligadas o relacionadas solo por vecindad, que no solo confluyen sino que son una única historia: un matrimonio que vive la desaparición de su hija adolescente, un vecino y su hijo enfrentados desde la muerte de la madre y, además, una pareja de ancianos que rememoran el pasado.

Estoy interesada en la naturaleza humana y en lo que impulsa a la gente a actuar de extrañas maneras en determinadas situaciones. En mi escritura trato de explorar los rincones más oscuros del individuo, indagar en sus miedos, sus obsesiones, sus deseos, siempre desde un contexto reconocible, en el que el espectador se pueda sentir identificado, dejando un espacio para lo imaginario y lo poético. [...] Quería escribir sobre la ausencia y terminé escribiendo una historia de amor (Dumitrache 2017).

De nuevo hay que leer la obra presuponiendo que todos los deseos que se enuncian son un peligroso futurible satisfecho: "ALBA. ¿No podríais ser unos padres normales? LA MADrE. ¿Qué quiere decir 'normales'? Alba. Divorciados.” Efectivamente, "durante los largos días angustiosos en que [Alba] se encuentra en paradero desconocido, la relación de sus padres se agrieta y se degrada” (Puigtobella 2012). “Alba. ¡Bah! No podríais vivir sin mí. La Madre. Sí que podríamos". Esta prolepsis se relaciona con otra muy cercana del padre, una vez que ya ha desaparecido: "Van a encontrarla en alguna parte y nos la traerán de vuelta”. El imaginario recorre la obra: “ ¿Y si tiene hambre? ¿Y si tiene miedo? [...] Puede haber tenido un accidente [...] Tenía que estar aquí, ahora mismo, en su cuarto con la música a toda hostia. [...] Nada es como antes. [...] Yo creo que mi hija está en ese bosque". Efectivamente, el hijo del vecino, que está enamorado de ella y de quien la madre sospecha, la encontrará bajo la hojarasca,

9 "Fabulamundi. Dramaturgia Europea es un proyecto ganador del Programa Cultura 2007-2013 y tiene como objeto promover la dramaturgia contemporánea, traductores, dramaturgos y sus textos, con la ayuda de las instituciones teatrales de Italia, Francia, España, Alemania y Rumanía. Fue iniciado por la Asociación PAV en Roma y los co-organizadores son Off Limits (Madrid, España) y el Teatro Nacional en Târgu Mureş" (Anónimo 2014a). 
en el bosque (lugar simbólico y ancestral donde los haya). Cuando la encuentra Alba no tiene ojos y su cuerpo está inmóvil:

La que está tumbada en ese hospital no es mi hija. [...] Es un pedazo de cuerpo destrozado. [...] Mi hija no puede estarse quieta. [...] Es impertinente hasta desesperar. Toda la casa retumba cada vez que se ríe. [...] Esa que nos han traído de vuelta no es Alba. [...] Yo quiero a mi hija. O viva o muerta. Pero no así. [...] PAdRe. ¿ No la quieres? La MAdre. No. [...] Mi hija desapareció en el bosque y no volvió nunca de allí.

Las prolepsis se cumplen así; de nuevo, el deseo que se verbalizó: "No podríais vivir sin mí. LA MAdRe. Sí que podríamos". Vivir sí, pero cómo. El amor que se tienen los dos ancianos, cuando descubrimos que ella es ciega y va en silla de ruedas, responde a esta pregunta.

El 3 de julio de 2012 se estrena Udol, en catalán Aullido, préstamo que toma Marilia Samper del extenso poema de Alan Gisberg Howl, debido a que una parte titulada "Mierda" está claramente inspirada en él. Se trata de una recopilación de textos "para Q-Ars Teatre para el [Festival] Grec [de Barcelona], que se representará dos días en el Espai Lliure [...] Es un espectáculo muy visual dirigido por Joan Maria Segura de Egos Teatre, básicamente de movimiento y música [...] un espectáculo que trata sobre el arte, [...] hay textos que son de humor, otros más poéticos" (Díez 2012). Curiosamente, otro de los textos se titula "Deseo": "El deseo me ha tocado. [...] Eso es para mí el acto de creación".

Entre 2013 y 2014 trabaja con varias compañías como dramaturga y directora, con las que repetirá en 2015 y 2016. Para Divinas escribe Paradis, que será dirigida por Martí Torras y estrenada en el Teatro Rubí de Barcelona (2013); se trata de un espectáculo musical que hace un recorrido por la música popular y tradicional de mediados del siglo XX, a la par que retrata la España franquista y su represión social, sexual y femenina (Fernández, 2015a). En 2014 para la misma compañía escribe y dirige Milim, espectáculo musical infantil que se estrena en Teatro de Arenys del Mar, Barcelona. Con la compañía de Sixto Paz dirige obras de distintos autores, la primera fue Si existeix, encara no ho he trobat de Nick Payne, estrenada en la Sala Beckett (2013); después, también en la Beckett, un año más tarde, repite con Pulmons de Duncan Macmillan, que gira sobre las diferencias de pareja ante la cuestión de tener o no hijos. La última colaboración como directora con esta compañía fue con la obra Pretty de Neil LaBute, que se presentó en la Sala Villaroel, permaneciendo en cartelera hasta el 12 de junio de 2016 (Coll 2016; Limones 2016). Con la compañía flamenca de Belén Maya en 2014 fue responsable de la dirección y dramaturgia de Ya!, espectáculo de música y danza que se estrenó en Teatre de Bescanó, Girona, y, en 2016, se encarga del espectáculo Romnia [Mujeres], con el título en rumano, una celebración del mundo gitano, estrenado en la Bienal de Flamenco de Sevilla ${ }^{10}$.

10 Todos estos espectáculos pueden consultarse en (Samper 2018). Medusa es un interesante espectáculo escrito para la compañía de Belén Maya, que se nombra en varias webs, el cual finalmente no se ha llevado a delante. 
Petits monsters es la segunda inclusión de Marilia Samper en el campo de la comedia, se estrena el 12 de julio de 2013 en la Nau Ivanow durante el Festival Grec de Barcelona, bajo dirección de Cales Fernández-Giua. La obra nació de una simple genialidad.

Cuatro dramaturgos tenían que escribir una pieza breve y situarla en un espacio de la sala: Marilia Samper eligió la azotea. La triada rectora de Coincidències estaba allí, haciendo honor a su nombre, y le pidieron que ampliara aquel episodio de 20 minutos. Ahora dura 40 [...] Vi Pequeños monstruos el pasado viernes, en el patio de una casa particular (Ordoñez 2014).

Se trata de una obra que retrata la crisis de los 40, un cómico retrato generacional, que la autora confiesa ha escrito para reírse de sí misma. La protagonista, Anna, es una artista conceptual en paro que no pinta nada, en la que Samper ha concentrado miedos, obsesiones, paranoias (Fernández 2015b). Un personaje hiriente, cínico, en ocasiones, y muy divertido, que explota cuando su hermana Marta, su polo opuesto, decide dejar a su novio vegano, obsesionado con el yoga, para volver al hogar paterno. En ese momento la guerra entre las dos hermanas por la pequeña habitación en casa de sus padres estalla (Anónimo 2015). La autora dirigirá de nuevo esta obra un año después, su versión se estrenó en la Sala Villaroel del 4 al 29 de abril de 2015. Como ocurre en Dos punkis i un vespino, el real-imaginario funciona irónicamente, en clave de humor, los deseos de unos y otros terminan haciéndose reales, a veces expresados en caliente: casarse, tener hijos, comer cuanto quieras, incluso: "Crece de una vez, Ana. Y empieza a comportarte como una adulta”. Cabe decir que la vida es la última en reírse.

Escribe y dirige Líneas, una propuesta de teatro radiofónico producida por el Teatre Lliure y Catalunya radio, que se presentó el 4 de enero de 2015 dentro del proyecto Ondas libres. Proyecto de teatro radiofónico en el que "cuatro dramaturgos, Marc Artigau, Manuel Dueso, Jordi Oriol y Marilia Samper, han aceptado el encargo de este teatro para escribir y dirigir, cada uno, una pieza pensada para las ondas, de 30 minutos cada una. [...][Las cuales,] en presencia de público, serán leídas y grabadas dos piezas en cada sesión” (Anónimo 2014b). El real-imaginario es evidente en el desenlace de la obra. Gira sobre la relación de una hija que apenas conoce a su padre, recién salido de la cárcel, en ningún momento se dice cuál es su delito, solo: "Siempre se comportó con nosotros como un padre. Nunca nos hizo nada". De hecho, esto hace que el imaginario también opere en la mente del espectador-radioyente. En cierto momento ella teme lo que aquel hombre podría hacerle ("Notó el miedo en mí como un perro"). Y es que ese miedo se ha vuelto una realidad, desde el momento en que lo siente. La obra "es una reflexión en torno a los límites que establecemos, a nuestros prejuicios y hasta dónde nuestra ética personal nos permite llegar" (Samper 2018).

El periplo desde 2013 hasta 2014 de la obra Animals de companyia de Estel Solé, por unas setenta casas particulares, fue responsabilidad como directora de 
Marilia Samper y de la compañía La Mandangan, razón por la que fue motivo de un reportaje por RTVE (Anónimo 2014c), ejemplo, junto a otras obras, como la ya citada Petits monsters, del circuito más underground del teatro en Barcelona (Rubià 2015). En 2016 capitanea la tercera edición de Libràlegs, teatro para bibliotecas, un ciclo dentro del festival teatral de otoño de Girona, Temporada Alta, siendo responsables de los textos C. Clemente, P. Riera, J. Yago y la propia Samper, que tienen por objeto un diálogo entre los autores y sus personajes (Anónimo 2016a) ${ }^{11}$. Ese mismo año dirige la obra del autor checo Václav Havel, Vernissatge ${ }^{12}$, con la compañía La Trama Produccions, que se representó del 21 de diciembre de 2016 hasta el 15 de enero de 2017 en el teatro Maldà. "Vernissatge merece nuestra atención. Por su dirección milimétrica y por la labor de sus intérpretes, pero también por el acercamiento a un autor determinante e injustamente desconocido para muchos" (Solla 2017).

La primera obra programada en la nueva sede de la Sala Becket ${ }^{13}$ fue Kilòmetres, del 29 de septiembre al 16 de octubre de 2016, un monólogo donde la actriz Meritxell Yanes representa múltiples personajes. Esta obra es iniciativa de la propia actriz que, a raíz de la muerte de su abuela, Encarnación Alemany Pla, en 2014, pide ayuda a Marilia Samper para convertir en obra de teatro la vida de sus abuelos (Anónimo 2016d). En Kilòmetres el real-imaginario se mueve a medio camino entre lo transmitido, presente a manera de hecho reales: cartas, diarios o la narración en estilo directo de su abuela, y lo imaginario, articulado a modo de "quizás", ensoñaciones y suposiciones. Videos, audios y Google se convierten en herramientas de verificación. “¿Dónde estabas el 18 de julio de 1936?", así empieza la historia. "Escribo historias [...] para plantear una pregunta que no pretende encontrar respuesta" (Samper 2015).

Marilia Samper es la primera autora residente de la nueva Sala Beckect en la temporada 2016-17, durante la cual escribió L'Alegria, estrenada del 9 de octubre al 12 de noviembre de 2017. La protagonista, Júlia, madre de un hijo con parálisis cerebral, requiere de la construcción de una rampa, ya no puede llevarlo en brazos. Pero "una simple rampa puede resultar una empresa imposible [...] si su consecución depende de la voluntad y bondad de los demás” (Anónimo 2017c).

11 En 2013 "Jordi Prat i Coll y Temporada Alta crearon una palabra nueva y un nuevo espectáculo: Llibràlegs" (Anónimo 2016b). Temporada Alta es un festival de artes escénicas que se celebra en Girona y Salt durante los meses de octubre, noviembre y diciembre. Ha sido calificado como el mejor festival de España por la prensa especializada.

12 "Prohibido en su momento, el texto nos habla de la hipocresía de la denominada autorrealización personal, máscara del conservadurismo más arraigado" (Anónimo 2016c). Václav Havel es el autor de Carta 77, movimiento por los derechos civiles que él mismo lideró. Vernissatge se escribió en 1975, durante un fuerte período de represión posterior a la Primavera de Praga de 1968.

13 La "Sala Becket [...] [ha seguido] su proyecto de favorecer la escritura contemporánea, desde cursos de formación y especialización, hasta la producción y programación en su sala. [...] [Otros] proyectos genuinos y fructíferos como el T6 del Teatre Nacional [...], finalmente los han aniquilado" (Samper, 2016). 
La obra implica una reflexión sobre el tejido comunitario; la autora lo advierte: “a mí no me gusta plantear héroes [...] aquí nadie es un héroe" (Cortina 2017). Se trata de una obra "escrita con gran sabiduría compositiva: logra el prodigio de parecer sencilla” (Ordoñez 2017), todo nace de un simple deseo. El hijo, Eli, se desdobla en media docena de personajes, incluyendo al narrador y rompiendo la cuarta pared. De hecho, el real-imaginario pasa por este juego del narratario, que enuncia lo que se va a ver, se vuelve descriptivo o cuenta un final alternativo, imaginario que se vuelve real en el corazón de los espectadores.

\section{Bibliografía}

Anónimo, s.f. ${ }^{14}$ a, "Històric de beques i premis per a graduats" Institut del teatre, <https://www.institutdelteatre.cat/ca/graduats/thm31/pag1222/pl485/ serveis-per-alumnes/id26/historic-de-beques-i-premis-per-a-graduats.htm.>

Anónimo, s.f.b, “Companyia. Parking Shakespeare” [página web de la compañía], $<$ http://www.parkingshakespeare.com/companyia/>.

Anónimo, 2011a, "Marilia Samper-TNC”, Projecte T6. Sisena edició 2011/2013, $<$ https://www.tnc.cat/uploads/20110906/CV_Marilia_Samper.pdf>.

Anónimo, 2011b, "F3dra. Pleasure and Pain de Marilia Samper", Q-Ars Teatre, 31/07/2011, <http://qarsteatre.blogspot.com.es/2011/07/f3dra-pleasure-andpain-de-marilia.html $>$.

Anónimo, 2012a, "El teatro de la emoción”, La Vanguardia 14/05/2012, <https:// www.pressreader.com/spain/la vanguardia/20120514/282578785073125>.

Anónimo, 2012b, "F3dra (Pleasure \& pain), de Marilia Samper Cia. ArsTeatro (Espectacles)", [web del Ayuntamiento de Vilafranca del Penedès], 26/11/2012, <http://www.vilafranca.org/jsp/agenda/detall.jsp?id=9483>.

Anónimo, 2014a, "Umbre cu Marilia Samper și noua dramaturgie europeană”, Yorick.ro. Revista online du teatru, 19/02/2014., <https://yorick.ro/umbre-cumarilia-samper-si-noua-dramaturgie-europeana/ $>$.

Anónimo, 2014b, "Ones Lliures amb textos de Marc Artigau, Manuel Dueso, Jordi Oriol i Marilia Samper [dossier]", Teatre Lliure, temporada 2014-2015, $<$ http://www.teatrelliure.com/sites/default/files/espectacles/dossiers/dossier_ ones_lliures.pdf>.

Anónimo, 2014c, "Repor - El espectáculo debe continuar - Animals de companyia”, Televisión a la carta, 31/03/2014, <http://www.rtve.es/alacarta/ videos/repor/repor-espectaculo-animals-companyia/2479289/>.

Anónimo, 2015, “La Villarroel estrena hoy Petits Monstres”, EnPlatea, 05/03/2015, $<$ http://enplatea.com/?p=4636>.

14 Sin fecha. 
Anónimo, 2016a, "El III Llibràlegs porta el teatre a les biblioteques", El Punt Avui, 02/11/2016, <http://www.elpuntavui.cat/cultura/article/19-cultura/1017942el-iii-llibralegs-porta-el-teatre-a-les-biblioteques.html $>$.

Anónimo, 2016b, "Marilia Samper agafa el relleu en la dirección d'aquest experiment teatral a les biblioteques", Festival Temporada Alta, $<$ http://www. temporada-alta.net/ca/prograacio/589-llibralegs-iii.html>.

Anónimo, 2016c, "El Maldà cierra el año con dos estrenos", EnPlatea, 19/12/2016, $<\mathrm{http}$ ://enplatea.com/?p=10725>.

Anónimo, 2016d, "La nueva Sala Beckett presenta su primer título", EnPlatea, 21/09/2016, <http://enplatea.com/?p=10068>.

Anónimo, 2017a, "Masterclass de Marilia Samper", Creadores.es., <http:// creador-es.com/creador-es-2017/masterclass-marilia-samper/>.

Anónimo, 2017b, “Umbre, o poveste de dragoste aproape incredibilă, în premieră pe țară la TNB”, Rfi.România, 30/05/2017, <https://rfi.ro/eveniment-95536umbre-o-poveste-de-dragoste-aproape-incredibila-premiera-pe-tara-la-tnb $>$. Anónimo, 2017c, "La Sala Beckett estrena un texto sobre la precariedad y la pobreza", EnPlatea, 09/10/2017, <http://enplatea.com/?p=14111>.

Armengol, M., s.f., "Marilia Samper parla sobre Dos punkis $i$ un vespino", Teatralnet. Revista digital d'arts escèniques, <http://www.teatral.net/asp/ traientpunta/index.asp?idtraient $=141>$.

Barbany, P., 2012, "Marialia Samper se estrena en el T-6 del Teatre Nacional de Catalunya con L'ombra al meu costat", Notodo.com, 14/05/2012, <http:// www.notodo.com/escena/teatro_contemporaneo/3530_lombra_al_meu_ costat_teatre_nacional_de_catalunya_barcelona.html $>$.

Barderi, M., 2015, "Marilia Samper: «Las obras maestras salen del alma, no del bolsillo»", Núvol. El digital de cultura, 05/01/2015, <https://www.nuvol. com/entrevistes/marilia-samper-las-obras-maestras-salen-del-alma-no-delbolsillo/>.

Basbaum, H.W., Samper, M. \& Lara Puiati, T., 2008, 6 Concurso Nacional de Dramaturgia Prêmio Carlos Carvalho [El Señor de parís. Un verdadero vaquero. Cara a tapa], Porto Alegre, Editora de Cidade, vol. 1.

Bouman, 2011, "Os punkis i un vespino", Under Brain, 19/12/11, <https:// underbrain.com/teatro/dospunkisiunvespino/>.

Busto, J., Salvatierra, J.A. \& Samper, M., 2002, El día de autos. El rey de Algeciras. Menú del día (Premio Marqués de Bradomín), Madrid, Naque.

Campos Gallego, P., Samper, M. \& Gomar, J., 2001, La herida en el costado. 405. Superhéroes de barrio (Premio Marqués Bradomín), Madrid, Naque.

Coll, M., 2016, "Marilia Samper: «Vivim esclavitzats per l'oponió dels alters»", Valors. Diari digital d'ètica i reflexió promogut per la revista Valors, 18/05/2016, $<$ http://www.valors.org/marilia-samper-vivim-esclavitzats-per-lopinio-delsaltres/>. 
Cortina, P., 2017, “L'alegria con Sergi Torrecilla y Marilia Samper”, Dramedias. Ilustres espectadores, España, Radio3, 15/10/2017, 20:22 mints, <http://www. rtve.es/alacarta/audios/dramedias/ilustres-espectadores-marilia-2017-1011t18-09-08560/4255661/>.

Díez, E., 2012, “Mis textos son siempre viajes emocionales”, Butaques $i$ somnis, $<$ http://butaquesisomnis.blogspot.com.es/2012/05/mis-textos-son-siempreviajes.html>.

Dumitrache, M., 2017, “Umbre. Un spectacol despre speranță”, Webcultura, 09/96/2017, <http://webcultura.ro/infinitele-nuante-ale-umbrelor/>.

Eagleton, T., 2017, Cultura, Barcelona, Taurus.

Fernández, I., 2015a, “Ole!, las Divinas”, El periódico, 03/01/2015, <http:// divinas.cat/noticies/el-peirodico-paradis/>.

Fernández, I., 2015b, "La risa del desencanto", El periódico. Edición de Catalunya. Edición global, 04/03/2015, <http://www.elperiodico.com/es/ocio-ycultura/20150303/la-risa-del-desencanto-3986628>.

Ginart, B., 2005, "El nuevo proyecto T6 del TNC, de ayuda a la dramaturgia actual, arranca la próxima temporada”, El País. Cataluña, 22/12/2005, $<$ https://elpais.com/diario/2005/12/22/catalunya/1135217260_850215.html>.

Ilis, M., 2017, “Umbre, inca un succes rasunator al T.N.B.”, Jurnal Ulbucurestiului, 09/06/2017, <http://jurnalulbucurestiului.ro/umbre-inca-un-succesrasunator-al-t-n-b/>.

Lapeña, A.A., 1996, "El Instituto del Teatro de Sevilla. Quince años en la enseñanza del arte dramático", ADE teatro: Revista de la Asociación de Directores de Escena de España, no 54-55, 1996, p. 83-88.

Limones, D., 2016, "Ser, o no ser... Pretty por dentro y por fuera", EnPlatea, 08/06/2016, <http://enplatea.com/?p=9191>.

Ordoñez, M., 2014, “Samper al aire”, El País, 08/10/2014, <https://elpais.com/ cultura/2014/10/08/actualidad/1412785602_667508.html>.

Ordoñez, M., 2017, “Teatro para tiempos convulsos”, Babelia. El País, 22/10/2017, $<$ https://elpais.com/cultura/2017/10/26/babelia/1509022869_733939.html>.

Puigtobella, B., 2012, "L'ombra de Marilia Samper", Núvol. El digital de cultura, 03/05/2012, <https:/www.nuvol.com/noticies/marilia-samper-t-6-teatrenacional-sala-tallerss/>.

Rubià, M., 2015, "Baños, azoteas y hoteles: cuando el teatro no se hace en el teatro", Teatre Barcelona, 20/01/2015, <https:/es.teatrebarcelona.com/ revista/cuines-terrats-hotels-quan-el-teatre-no-es-fa-al-tatre\#more-19938>.

Rubio, S., Samper, M. \& Gutiérrez, P., 2001, Silencio. 405. Carne de cerdo, Sevilla, Centro Andaluz de Teatro y Centro de Documentación de las Artes Escénicas de Andalucía, col. "Premio Miguel Romero Esteo" no 2.

Salvatierra, J.A., Samper, M. \& Montero, D., 2002, El rey de Algeciras. Menú del día. Lullaby, Sevilla, Centro Andaluz de Teatro y Centro de Documentación 
de las Artes Escénicas de Andalucía, col. "Premio Miguel Romero Esteo" núm. 3.

Samper, M., 2012, L'ombra al meu costat, Tarragona, Arola Editors [traída por referencias].

Samper, M., 2015, "Lo contemporáneo y la estupidez", (Pausa.) Quadern de Teatre Contemporani, no 37, <http://www.revistapausa.cat/lo-contemporaneo-y-laestupidez/>.

Samper, M., 2016, "El futuro incierto de nuestra dramaturgia", Teatre Barcelona, 14/03/2016, <https://es.teatrebarcelona.com/revista/futuro-incierto-nuestradramaturgia $>$.

Samper, M., 2018, “Bio. Premios. Espectáculos” [página web de Marilia Samper], <http://www.mariliasamper.com/bio/>.

Sanchis Sinesterra, J. (coord.), 2008 [Pilar Campos, Ignasi García, Damarís Matos, Gracia Morales, Juan Alberto Salvatierra y Marilia Samper], La orilla perra del mundo. Teatro del común, Madrid, Akal.

Sanchis Sinesterra, J., Vázquez Honrubia, A. \& Luque, Maj., 2008, La orilla perra del mundo. Teatro del común. Cuaderno Pedagógico, Madrid, Akal.

Solla, F., 2017, “Objetos hermosos, sujetos vacíos”, EnPlatea, 09/01/2017, <http:// enplatea.com/?p=10895>.

Zurro, A. (ed.), 2006, 60 obras de 1 minuto de 60 autores dramáticos andaluces, Sevilla, Empresa Pública de Gestión de Programas Culturales-CDAEA. 